\title{
A Place for Patterning in Cognitive Development
}

\section{K. Marinka Gadzichowski, Matthew S. Peterson, Robert Pasnak, Allison M. Bock, Sarah 0’Brien Jacobs Melissa Fetterer-Robinson, Katrina Lea Schmerold}

Department of Psychology, George Mason University, Fairfax, Virginia, USA

Email: rpasnak@gmu.edu

How to cite this paper: Gadzichowski, K. M., Peterson, M. S., Pasnak, R., Bock, A. M., Fetterer-Robinson, S. O. J. M., \& Schmerold, K. L. (2018). A Place for Patterning in Cognitive Development. Psychology, 9, 2073-2082.

https://doi.org/10.4236/psych.2018.98118

Received: July 6, 2018

Accepted: August 6, 2018

Published: August 9, 2018

Copyright $\odot 2018$ by authors and Scientific Research Publishing Inc. This work is licensed under the Creative Commons Attribution International License (CC BY 4.0).

http://creativecommons.org/licenses/by/4.0/

\section{Open Access}

\begin{abstract}
"Patterning" is a cognitive intervention that is unknown to psychologists, but has nevertheless been taught for half a century in nearly all kindergartens and many preschools in English-speaking countries. Patterning is the understanding that a certain rule governs the sequence of items in a series. At the simplest level, if the series has been red, tan, red, tan, red, tan, the next item should be red. More advanced patterns- "growing" geometric patterns and complex patterns of letters, numbers, and objects-have also been studied. Patterning is thought by educators to be a key cognitive ability that promotes academic achievement. However, its relative position in the hierarchy of cognitive developments is unknown. The present study showed that it is closely related to both transitivity and seriation, and that size transitivity problems best expressed the common factor that predicted patterning scores.
\end{abstract}

\section{Keywords}

Seriation, Transitivity, Patterning, Cognitive Development

\section{Introduction}

What cognitive intervention is most widely employed in American schools? In what cognitive intervention have nearly all psychologists younger than 50 participated? What cognitive intervention have those psychologists never heard of? The answer is "patterning". For more than 50 years it has been taught in the vast majority of preschools and kindergartens in the United States as a form of cognitive intervention. Improving children's abilities to understand patterns is thought to improve children's understanding of mathematics concepts and (perhaps) reading.

Patterning is the understanding that items in a series may follow a certain 
rule, and that the same rule may apply to other series regardless of the nature of the items in the series. It is usually introduced first as simple alternations: items may alternate in color, being blue or pink: e.g. blue pink blue pink blue pink. Or they may alternate in size, being big or small: big small big small big small. Or they might alternate in shape: disk, square, disk square disk square. All of these series, although differing in concrete items, can be understood by the same abstraction: ababab, and can be extended or copied with different items or have missing items filled in by understanding and applying the abstraction. Manuals for teaching children are available (Burton, 1982; Jarboe \& Sattler, 2003) and children progress to aabaab, abbabb, abcabc, and aabbaabb abstractions. This instruction has been recommended by national organizations (National Council of Teachers of Mathematics (NCTM), 1993; National Governors Center for Best Practices, 2010; National Association for the Education of Young Children/NCTM, 2002/2010). It has been supported by educational consensus, and educators, especially Clements and Sarama (2007 a, b, c, d), Clements and Sarama (2009), McGarvey (2012), Papic (2007), Threlfall (1999), and many others, have advanced cogent arguments as to why it should be related to early mathematics. However, psychologists who study cognitive development appear to have been completely unaware of patterning. Its relation to other cognitive constructs is unknown. Although research has begun with more complex patterns, and advanced forms of patterning have been shown to be important in the development of reading and mathematics, until very recently there have been very few empirical studies of patterning as a cognitive development. No theory defines its place among the sequence of abilities mastered during cognitive development.

For many years the only empirical evidence that patterning was related to academic achievement was an unpublished dissertation by an educator (Herman, 1973). Her study indicated that instruction in patterning might have improved children's mathematics skills. However, the study was flawed-the control children cam e from a different school than the experimental children-and seems to have been ignored. Thirty years later Hendricks, Trueblood, and Pasnak (2006) employed a design in which children were randomly assigned to be taught patterning or academic material recommended by their teachers. Their statistical analysis indicated that the patterning instruction was most effective in improving improved mathematics and written language. More recently, Kidd et al. (2013), Kidd et al. (2014), and Pasnak et al. (2015), replicated and extended these results. The patterns employed in this instruction were series of objects, letters or numbers that increased in size, position in the alphabet, or value, clock faces that showed increasingly later times, or objects that rotated through six or eight positions.

Studies of the relations between patterning and other abilities have been focused on mathematics. For example, Clements and Sarama (2007c) incorporated it into their learning trajectories approach; Rittle-Johnson, Fyfe, Hofer, and Farren (2017) showed that early (preschool) knowledge of patterning predicted fifth grade mathematics achievement, and Lee, Ng, Bull, Pe, \& Ho (2011) applied a 
series of structural equation models to show that understanding number patterns of varying complexity $(42,668,43,668$, ?, 45,668, 46,668 is one of the simplest) and algebra correlated for Singaporean 10-year-olds. However, in the last two years studies of patterning's relation to other processes have been published. There have been two studies of simple repeating patterns and one of more complex patterns that explored the relation of patterning to three executive functions (EF). These three EF are working memory (the ability to hold and manipulate information just acquired); inhibition (the ability to suppress prepotent responses in favor of those more task-appropriate); and cognitive flexibility (the ability to shift the basis on which responses are made). Although they are correlated, these three EF are distinguishable (Duan, Wei, Wang, \& Shi, 2010) and continue to develop into adulthood. The results for patterning have conflicted. For preschoolers, Collins and Laski (2015) found that working memory and inhibition were related to patterning; the effect of cognitive flexibility was not assessed. Miller, Rittle-Johnson, Loehr, and Fyfe (2015) found that cognitive flexibility as well as working memory correlated with preschoolers' patterning abilities but did not find a correlation for inhibition. Schmerold et al. (2017), studying first graders with the complex patterns used by Kidd et al. (2014) and Pasnak et al. (2015), also found that cognitive flexibility and working memory were correlates of patterning ability. Inhibition was not. However, the effect of cognitive flexibility on reading and mathematics, earlier reported by Kidd et al. (2014) and Pasnak et al. (2015) was entirely mediated by patterning. This suggests that patterning is a type of thinking in its own right, rather than simply a correlate of other thinking abilities.

Whatever the relations between the cognitive processes known as EF and patterning turn out to be, the place of patterning among the hierarchy of conceptual abilities children develop has not been addressed in any research. One possibility is provided by the venerable Piagetian framework, which addresses two other aspects of serial ordering. Piaget and Inhelder (1973), for example, theorized that unidimensional seriation - the ordering of objects along one dimension by their magnitude (such as length or width or weight) was a preoperational development until an explicit understanding of transitivity developed. (This definition came after several earlier efforts to define the point at which seriation became operational.) Thus, success in unidimensional seriation, which can be accomplished by simple approaches (Piaget \& Inhelder, 1969), was theoretically a precursor to, but not the equivalent of, transitivity.

Hendricks et al. (2006) advanced the possibility is that understanding patterns is intermediate between seriation and transitivity. In seriation, items either increase or decrease in one physical dimension. In patterning the relation is more complex; it might involve size, color, shape, numbers, or letters, and can be much more complicated. Transitivity, a more advanced reasoning ability, is the understanding that if $\mathrm{A}$ is related to $\mathrm{B}$ and $\mathrm{B}$ is related to $\mathrm{C}$ on some dimension, then the relation between $\mathrm{A}$ and $\mathrm{C}$ can be deduced by comparing $\mathrm{A}$ to $\mathrm{B}$ and $\mathrm{C}$ to $B$ if the relation between $\mathrm{A}$ and $\mathrm{C}$ cannot be directly observed. Both transitivity 
and patterning incorporate the idea that an item is defined by, and simultaneously defines, properties of items that follow or precede it. The primary difference between transitivity and patterning is that transitivity requires children to utilize the relations of $\mathrm{A}$ to $\mathrm{B}$ and $\mathrm{C}$ to $\mathrm{B}$ in deducing the relation of $\mathrm{A}$ to $\mathrm{C}$. Patterning does not require utilization of those relations to make that deduction. Children could make use of the transitive relation or make use of the simultaneous presentation of all items and compare $\mathrm{A}$ to $\mathrm{C}$ directly to solve a patterning problem. Hence, Hendricks et al. (2006) suggested that patterning is probably less demanding cognitively than transitivity.

Because patterning is also a serial ordering of objects it seemed likely that patterning was related to either seriation or transitivity or both. The present research was an effort to determine those relations empirically. The project was, however, also an effort to call the attention of developmental psychologists to patterning, a cognitive intervention that is very common in elementary schools.

\section{Method}

\subsection{Participants}

After the research was approved by the university's Institutional Review Board and the Accountability Office of the school system, permission letters were sent to parents and returned. The children were first-graders from two public schools in an urban school district next to a large city in the mid-Atlantic region. Many were from immigrant families; more than 30 different languages are spoken by the children in this system. More than half of the 62 children received subsidies for housing, food, and or school lunches. Their average age when the research was conducted (spring) was 6 years, 7.1 months; 32 were boys, and 30 were girls. Of these, 23 (37.1\%) were African American, 24 (38.7\%) were Hispanic/Latino, 7 (11.3\%) were Middle Eastern, 3 (4.8\%) were other Caucasian, and 5 (8.1\%) were of an unspecified ethnicity.

\subsection{Materials}

Flip charts were used to present 48 patterns of five numbers, letters, time as represented on clock faces, or objects presented in rotated positions in which either one or two steps in value or rotation were skipped. Examples are J, L, $-\mathrm{N}$, P or _ 3, 6, 9, 12, or 2 O'Clock, 3 O'Clock, 4 O'Clock, __ or an object upright, then rotated 30 degrees, 90 degrees, 120 degrees. One third of the patterns were increasing in the dimension they expressed, one third were decreasing in that dimension, and one third were symmetrical.

Patterns were constructed in vertical or horizontal orientations equally often, and the four possible alternatives for the missing item from which the child was to choose also occurred equally often. Randomization of the patterns would inevitably have resulted in some types being presented earlier, on the average, than others, so type of pattern, orientation, and steps between items were carefully counterbalanced on the flip charts. 
Flip charts were also used to present 24 seriation problems, which also consisted of five items, with the first, middle, or last item missing, and four alternatives from which to select the missing item, in counterbalanced orders. The problems were made of different colors and shapes to maintain children's interest, but the seriated items and the alternatives for each problem always varied in $1.27 \mathrm{~cm}$ steps in height.

Another flip chart was used for a set of 24 size transitivity items. That is, a small item was $1.27 \mathrm{~cm}^{2}$, the next $2.54 \mathrm{~cm}^{2}$, the next $3.81 \mathrm{~cm}^{2}$, the next $5.08 \mathrm{~cm}^{2}$, and the largest $6.35 \mathrm{~cm}^{2}$. The chart might have one pair of items, for example an orange $1.27 \mathrm{~cm}$ square and a blue $2.54 \mathrm{~cm}$ square. The next page of the chart would have the same blue square and a $3.81 \mathrm{~cm}$ black square. Then the next page would be blank and the question asked, which was larger, the black one or the orange one? The order of presentation of the pairs and use of the terms larger and smaller was counterbalanced.

A fifth flip chart was used for a set of 24 height transitivity problems. The items were each $2.54 \mathrm{~cm}$ wide. They had different colors and shapes, but varied in height by $1.27 \mathrm{~cm}$. steps. For example, one pair of items was a $2.54 \times 3.81 \mathrm{~cm}$ yellow rectangle and a 2.54 and 5.08 red rectangle. The next pair was a $2.54 \times$ $5.08 \mathrm{~cm}$ red rectangle and a green $2.54 \times 6.35 \mathrm{~cm}$ rectangle. Then, presented with a blank card, the child would be asked, which was taller (shorter), the yellow one or the green one? Again, the order of presentation of the pairs and use of the terms taller and shorter was counterbalanced

\subsection{Procedure}

The tests were administered in quiet rooms to one child at a time by trained research assistants. Each child had one 10 - 15 minute session of testing per day, during the morning. The order of administration of the seriation, height transitivity, size transitivity, and patterning test was counterbalanced. A total of 24 possible orders exists, so each was used at least twice. The seriation test and the two transitivity tests each took one session. To prevent fatigue or loss of interest; the 48-problem patterning test was administered in two 10 - 15 minute sessions. Hence, 24 patterning problems were presented in one session, and the other 24 patterning problems in the next subsequent session. Altogether, the testing required five sessions per child, which, because children were sometimes absent or otherwise unavailable for testing, were spread over six weeks. One child did not complete the patterning test but did complete the others.

In sum, each child was tested five times, in 10 - 15 minute sessions involving 24 problems each, to secure four scores: seriation, size transitivity, height transitivity, and patterning.

\section{Results}

The scores for the 48-problem patterning test were divided by two to make means for all measures comparable. Three findings emerged. 
First, the children had not mastered any of these concepts, averaging only 17.22 problems correct, $\mathrm{SD}=2.54$, or $72 \%$, on the seriation test, 9.78 correct, $\mathrm{SD}=$ 2.99 on the transitivity overall size test $(41 \%), 10.93$ correct, $\mathrm{SD}=2.72$ on the transitivity height test (46\%) and the equivalent of $9.49, \mathrm{SD}=3.70$ on the patterning test (40\%).

Second, the differences in means were, with one exception, significant. The seriation mean was significantly higher than the mean for transitivity overall size problems, $t(59)=29.77, p<.001$, and also that for the transitivity height problems, $t(59)=25.67, p<.001$. The seriation mean was also significantly higher than that for the patterning problems (adjusted for the number of problems on the tests), $t(58)=22.64, p<.001$. Hence, seriation was easier for the children than patterning and transitivity.

Although the difference was slight, the mean for transitivity height problems was significantly higher than the patterning mean, $t(58)=4.67, p<.001$. That for transitivity overall size problems was not, $t(58)=1.37, p>.05$. Thus, transitivity was somewhat less difficult than the patterning problems, or as difficult, depending on the dimension in which the transitivity problems were presented.

In sum, the seriation problems were easier for these first graders than the other problems, and the transitivity problems were somewhat easier than the patterning problems.

Third, and most strikingly, scores on all three concepts were highly correlated. Scores on seriation correlated with scores on patterning, $r(57)=.71, p<.005$, transitivity height problems, $\mathrm{r}(58)=.74, p<.001$, and transitivity overall size problems, $r(58)=.77, p<.001$. Patterning scores likewise correlated with transitivity height problems, $r(57)=.73, p<.001$, and transitivity overall size problems, $r(57)=.83, p<.001$. None of these correlations differ significantly from each other. They are noticeably higher than those usually seen in psychological research; Cohen (1972) regarded .50 as a strong effect size for $r$.

To get a better understanding of how these variables predict patterning scores, seriation and the two transitivity variables, as well as their interaction were entered into a multiple regression. Taken together, the overall model predicted the patterning scores (adjusted $r^{2}=0.690, F(1,55)=0.547, p<.001$ ), but the interaction was not significant $\left[r^{2}\right.$ change $\left.=.003, F(3,56)=41.616, p=.463\right]$. Only size transitivity was a significant predictor of patterning scores [Beta $=.758, \mathrm{t}(56)=$ $4.42, p<.001]$. In contrast, neither height transitivity [Beta $=-.094, t(56)=-.57$, $p=.57]$ nor seriation reached significance [Beta $=.192, t(56)=1.62, p=0.11]$.

\section{Discussion and Conclusions}

Although the analyses were simple, the outcome is clear. As measured in this experiment, for 6.5-year-old children, all tasks are related, and the relations between these abilities account for approximately half of the variation in scores. Size transitivity scores were best at capturing the common factor that predicts patterning. By themselves, seriation and each transitivity task was highly correlated 
with patterning. This can be considered evidence that the three abilities, seriation, patterning, and transitivity, express aspects of a common cognitive ability-competence in comprehending rule-governed sequences of stimuli. Strengthening this ability may be what the cognitive intervention currently practiced in American schools accomplishes, although this has not been advanced as a rationale for teaching patterning. Whether improving a child's understanding of patterns actually improves seriation and/or transitivity or vice versa has not been investigated.

The ordering of means obtained in this research suggests that Hendricks et al. (2006) may have been correct in their suggestion that understanding the serial order involved in patterns is a more advanced cognitive ability than seriation, but premature in suggesting that it preceded transitivity. Understanding the patterns used in this research was at least as difficult, or somewhat more difficult, than understanding the transitivity problems. Thus, comprehending and applying the more variable relations involved in the patterns was as taxing or more taxing than the demand for working memory that transitivity problems require. Schmerold et al. (2017) found that children's success on complex patterns correlated with their scores on measures of both working memory and cognitive flexibility. Cast in terms of executive functions, it may be that the simpler relation involved in transitivity problems, but the greater toll on working memory they exact, did not quite offset the greater need for cognitive flexibility but lesser demand for working memory the continuously visible patterns entailed.

It is also possible that some of the difficulty with the patterning problems resulted from the demands those problems made on knowledge of letters, numbers, and time as represented by clock faces. That subject matter is taught and supposed to be mastered in the first semester of kindergarten in the schools in which these children were enrolled, i.e. three semesters previously. It may nevertheless have been imperfect for some, and this may have lowered their scores on the patterning test.

The children made only half as many errors on the seriation problems as on the patterning and transitivity problems, despite factors in the tests that might have made the seriation scores more like those on the other constructs. Two thirds of the patterns were ascending or descending series, and the rest ascended then descended, albeit not in physical dimensions. They might be considered to be seriation problems more abstract than those usually used (Leiser \& Gillieron, 1990). Further, the transitivity problems are three-item seriation problems with a temporal component. Despite this, the errors on the seriation problems are much less frequent, while errors on the patterning and transitivity problems were roughly similar. The latter two operations are in a sense the inverse of each other. Transitivity involves using an intermediate item to relate neighboring items; patterning involves using neighboring items to define an intermediate item. This is one possibility but there are almost certainly others. In any event, 
both patterning and transitivity require more abstraction than seriation, and this may prove to be why they were more difficult.

Just what cognitive processes children are employing when they comprehend a pattern and subsequently apply the rubric they have comprehended remains to be determined. However, the relation of patterning to the constructs most like it is clarified by the present research. There are, of course, limitations to any investigation. One is that performance on all tests, and especially the patterning and transitivity tests, was low. It is possible that dissimilar results will be obtained by investigators working with samples of older or more able children. Another limitation is that there are an almost infinite number of possible patterns. Still another is that transitivity problems can involve more than three elements, and characteristics other than physical size. For that matter, seriation and patterning problems can be constructed which have temporal components, e.g. seriation of weights. However, in the present research, the simplest forms of transitivity problems were used, along with patterns much like seriation, so it is likely that the relations between seriation, patterning, and transitivity have been accurately identified. Sample differences are always an issue in developmental research, but the multi-ethnic nature of the sample suggests some generality for the finding that, for 6.5-year-olds, patterning is closely related to transitivity. However, the most important feature of this study is that it calls attention to patterning, a cognitive intervention that is entrenched in our schools but that has escaped the attention of psychologists. Educators have shown that early knowledge of patterning is especially predictive of later mathematics achievement (Rittle-Johnson, et al., 2017) and patterning has been incorporated into preschool activities (Clements \& Sarama, 2007c) that emphasize trajectories of mathematics learning. Because nearly all of our children experience interventions based on patterning, it deserves the attention of the best minds of all of the scientists who study thinking.

\section{Fund}

The research reported here was supported by the Institute of Education Sciences, U.S. Department of Education through Grant 305A170114 to George Mason University. The opinions expressed are those of the authors and do not represent views of the Institute or the U.S. Department of Education.

\section{Conflicts of Interest}

The authors declare no conflicts of interest regarding the publication of this paper.

\section{References}

Burton, G. M. (1982) Patterning: Powerful Play. School Science and Mathematics, 82, 39-44. https://doi.org/10.1111/j.1949-8594.1982.tb17161.x

Clements, D. H., \& Sarama, J. (2007a). Curriculum, Mathematics. In R. S. New, \& M. 
Cochran (Eds.), Early Childhood Education: An International Encyclopedia (Vol. 1, pp. 193-198). Westport, CN: Praeger.

Clements, D. H., \& Samara, J. (2007b). Early Childhood Mathematics Learning. In F. K. Lester Jr. (Ed.). Second Handbook on Mathematics Teaching and Learning (pp. 461-555). Charlotte, NC: Information Age.

Clements, D. H., \& Sarama, J. (2007c). Effects of a Preschool Mathematics Curriculum: Summative Research on the Building Blocks Project. Journal for Research on Mathematics Education, 38, 136-163.

Clements, D. H., \& Sarama, J. (2007d). Mathematics. In R. S. New, \& M. Cochran (Eds.). Early Childhood Education: An International Encyclopedia (Vol. 2, pp. 502-509). Westport, CN: Praeger.

Clements, D. H., \& Sarama, J. (2009). Learning and Teaching Early Math: The Learning Trajectories Approach. New York: Routledge.

Collins, M. A., \& Laski, E. V. (2015). Preschoolers Strategies for Solving Visual Pattern Tasks. Early Childhood Research Quarterly, 32, 204-214. https://doi.org/10.1016/j.ecresq.2015.04.004

Duan, X., Wei, S., Wang, G., \& Shi, J. (2010). The Relationship between Executive Functions and Intelligence on 11- to 12-Year-Old Children. Psychological Test and Assessment Modeling, 52, 419-431.

http://www.psychologie-aktuell.com/fileadmin/download/ptam/4-2010_20101218/o5_ Duan.pdf

Hendricks, C., Trueblood, L., \& Pasnak, R. (2006). Effects of Teaching Patterning to First Graders. Journal of Research on Childhood Education, 21, 77-87. https://doi.org/10.1080/02568540609594580

Herman, M. L. (1973). Patterning before Mathematics in Kindergarten. Dissertation Abstracts International, 33, 4060.

Jarboe, T., \& Sadler, S. (2003). It's as Easy as 1,2,3: Patterns and Activities for a Creative, Balanced Mathematics Program. Peterborough, NJ: Crystal Springs Books.

Kidd, J. K., Carlson, A. G., Gadzichowski, K. M. , Boyer, C. E., Gallington, D. A., \& Pasnak, R. (2013). Effects of Patterning Instruction on the Academic Achievement of First Grade Children. Journal of Research in Childhood Education, 27, 224-238. https://doi.org/10.1080/02568543.2013.766664

Kidd, J. K.,, Pasnak, R., Gadzichowski, K. M., Gallington, D. A., McKnight, P. E., Boyer, C. E., \& Carlson, A. (2014). Instructing First-Grade Children on Patterning Improves Reading and Mathematics. Early Education and Development, 25, 134-151.

https://doi.org/10.1080/10409289.2013.794448

Lee, K., Ng, S., Bull, R., Pe, M., \& Ho, R. (2011). Are Patterns Important? An Investigation of the Relationships between Proficiencies in Patterns, Computation, Executive Functioning, and Algebraic Word Problems. Journal of Educational Psychology, 103, 269-281. https://doi.org/10.1037/a0023068

Leiser, D., \& Gillieron, C. (1990). Cognitive Science and Genetic Epistemology: A Case Study of Understanding. New York: Plenum Press.

https://doi.org/10.1007/978-1-4684-5649-3

McGarvey, L. M. (2012). What Is a Pattern? Criteria Used by Teachers and Young Children. Mathematical Thinking and Learning, 14, 310-337. https://doi.org/10.1080/10986065.2012.717380

Miller, M. R., Rittle-Johnson, B., Loehr, A. M., \& Fyfe, E. R. (2015). The Influence of Relational Knowledge and Executive Function on Preschoolers' Repeating Pattern Know- 
ledge. Journal of Cognition and Development, 17, 85-104.

https://doi.org/10.1080/15248372.2015.1023307

National Association for the Education of Young Children/National Council of Teachers of Mathematics Education (2002/2010). Early Childhood Mathematics Education: Promoting Good Beginnings. Washington DC: NYAEC.

National Council of Teachers of Mathematics (1993). Curriculum and Evaluation Standards for School Mathematics Addenda Series, Grades K-6. Reston, VA: NCTM.

National Governors Association Center for Best Practices (2010). Common Core State Standards. Washington DC: Council of Chief State School Officers.

Papic, M. M. (2007). Promoting Repeating Patterns with Young Children-More than Just Alternating Colors. Australian Primary Mathematics Classroom, 12, 8-13.

http://www.aamt.edu.au/

Pasnak, R., Kidd, J. K., Gadzichowski, K. M., Gallington, D. A., Schmerold, K. L., \& West, H. M. (2015). Abstracting Sequences: Reasoning That Is a Key to Academic Achievement. Journal of Genetic Psychology, 176, 171-193.

https://doi.org/10.1080/00221325.2015.1024198

Piaget, J., \& Inhelder, B. (1969). The Psychology of the Child (H. Weaver Trans.). New York, NY: Basic Books.

Piaget, J., \& Inhelder, B. (1973). Memory and Intelligence (A. J. Pomeranz Trans.). New York, NY: Basic Books.

Rittle-Johnson, B., Fyfe, E. R., Hofer, K. G., \& Farren, D. C. (2017) Early Math Trajectories: Low-Income Children's Mathematics Knowledge from Ages 4 to 11. Child Development , 88, 1727-1742. https://doi.org/10.1111/cdev.12662

Schmerold, K. L. (2017). The Relations between Patterning, Executive Function, and Mathematics. The Journal of Psychology; Interdisciplinary and Applied, 151, 207-228. https://doi.org/10.1080/00223980.2016.1252708

Threlfall, J. (1999). Repeating Patterns in the Early Primary Years. In A. Orton (Ed.), Patterns in the Teaching and Learning of Mathematics (pp. 18-30). London: Cassell. 